\title{
Las tribus futboleras en la ciudad de Guadalajara: las barras de los equipos Atlas y Guadalajara en la actualidad
}

\author{
Rodolfo Humberto Aceves Arce
}

\begin{abstract}
Los grupos de aficionados al futbol denominados barras pueden caracterizarse como nuevas tribus urbanas amalgamadas por una fuerte vinculación emocional: la pasión compartida por un equipo de futbol. Este artículo, basado en entrevistas a líderes, muestra diferentes aspectos de algunos de estos colectivos que en la actualidad apoyan a los equipos Atlas y Guadalajara en la ciudad de Guadalajara: su origen, desarrollo, composición social, generacional y de género; su estructuración y relaciones internas, sus relaciones externas. Al mismo tiempo, se trata de comprender el papel que juega la afición de los miembros de estos grupos, en especial de sus líderes, en diferentes ámbitos de su vida cotidiana.
\end{abstract}

PALABRAS CLAVE: futbol, tribus, barras, grupos de aficionados, emoción compartida

\begin{abstract}
Football Fan Tribes in Guadalajara City: Barras of Atlas and Guadalajara Clubs at Present

Football fan groups, known as barras, can be characterized as new urban tribes conglomerated by a strong emotional link: the shared passion for a football club. This article, based on interviews to leaders of these groups, shows different aspects of some of these communities that currently support the Atlas and Guadalajara clubs, in Guadalajara City: their origins, development, social, generational, and gender composition; also, their structure, external and internal relationships. Simultaneously, it intends to comprehend the role that fondness has for these group members, and especially for leaders, in several spheres of their daily life.
\end{abstract}

KEYWORDS: football, tribes, barras, fan groups, shared emotion

RODOlfo Humberto ACEves ARCE: Candidato a doctor en ciencias sociales por el Centro de Investigaciones y Estudios Superiores en Antropología Social-Occidente, Guadalajara, México rodo70@yahoo.com 
$\mathrm{L}$ os propósitos del presente artículo, basado en entrevistas a líderes de grupos de seguidores de las principales escuadras tapatías de futbol, se centran en mostrar la manera en que ciertos aficionados de los equipos Atlas y Guadalajara dieron origen a los colectivos denominados barras, en exponer la forma en que se organizan y se relacionan, tanto interna como externamente, así como en señalar el origen social, el género y las edades de sus miembros.

Las entrevistas se realizaron entre los meses de septiembre y diciembre de 2004, como parte del proyecto de investigación "El futbol como conformador de identidades sociales en la ciudad de Guadalajara: los casos de las barras de los equipos Atlas y Guadalajara en la actualidad", apoyado por el Consejo Nacional de Ciencia y Tecnología (Conacyt) y el Centro de Investigaciones y Estudios Superiores en Antropología Social (CIESAS), que culminó con la tesis para obtener el grado de maestro en antropología social por el CIESAS-Occidente. Este estudio ha nutrido un campo de investigación relativamente nuevo en México, el de los estudios sociales del deporte, en especial del futbol, el cual empieza a mostrar un crecimiento significativo.

Para efectos de este artículo, usaremos la palabra tribu de acuerdo con la propuesta del sociólogo francés Michel Maffesoli (2004) $)^{1}$. El término tribu es utilizado de forma metafórica por este autor para caracterizar las transformaciones en que los grupos establecen lazos sociales. Para él, estos cambios tienen lugar en las sociedades posmodernas, opuestas a las sociedades modernas en diversos aspectos: la modernidad, caracterizada por lo social, por una estructura mecánica, por organizaciones sociales, por la función que los individuos cumplen en los agrupamientos contractuales, se opone a la posmodernidad, caracte-

\footnotetext{
${ }^{1}$ Se puede argumentar de manera general que, tradicionalmente, los antropólogos han utilizado el término tribu para describir a un "grupo autónomo, social y políticamente, de extensión definida, de homogeneidad cultural y organización social unificada que habita en un territorio que le pertenece" (Giner et al., 1998: 898). Su historia es larga y de significado variable: se ha utilizado para sustituir el término primitivo y evitar el calificativo de no estatal, así como para referirse a unidades políticas distintas de la etnia o la nación, lo que plantea un grupo en estado evolutivo o un grupo delimitado por una frontera estatal. Asimismo, el término carga una fuerte herencia colonial que conlleva un sentido de dominio y explotación de las metrópolis sobre las periferias (Ferguson, 2000: 522-523).
}

rizada por la socialidad, por una estructura orgánica y compleja, por las masas y por el papel que las personas desempeñan en las tribus afectuales. Así, las tribus consisten en grupos que se forman en las sociedades de masas ante el declive del individualismo, constituidos a partir del sentimiento de pertenencia, en función de una ética específica y en el marco de una red de comunicación. Estos grupos se establecen en, metafóricamente hablando, aldeas, territorios urbanos donde la gente se arraiga, se une, se solidariza, pero que también pueden ser territorios simbólicos de diversos tipos. En las aldeas, el santo patrono, figura tutelar que se venera y festeja, "es sustituido por el gurú, la celebridad local, el equipo de futbol o la secta de dimensiones modestas". Para Maffesoli, estos grupos no son estables, las personas que los componen pueden moverse entre una tribu y otra. El autor retoma el concepto weberiano de comunidad emocional como una categoría que puede servir como reveladora de situaciones presentes. Sus características son: aspecto efímero, composición cambiante, inscripción local, ausencia de organización y estructura cotidiana. Así, la conexión entre emoción compartida y comunalización abierta es la causante de la formación de múltiples grupos que acaban constituyendo una forma de vínculo social bastante sólido. De esta forma, alrededor de la permanencia e inestabilidad se articulará lo emocional (Maffesoli, 2004: 48, 57, 102, 242). En el desarrollo de este artículo observaremos algunas similitudes entre las nuevas tribus y los colectivos de aficionados denominados barras. De ahí el término tribus futboleras.

\section{LOS GRUPOS DE APOYO DE LOS EQUIPOS ATLASY GUADALAJARA EN LA ACTUALIDAD}

La rivalidad entre los equipos Atlas y Guadalajara se remonta a poco menos de un siglo, su enfrentamiento es considerado un clásico, el clásico tapatío, el más antiguo entre los antagonismos vigentes del futbol mexicano ${ }^{2}$.

\footnotetext{
${ }^{2}$ La palabra clásico, aplicada al universo futbolero, refiere a un partido trascendente por su relevancia histórica y simbólica. El origen del clásico tapatío se remonta a 1916, año en que por primera vez se enfrentaron el Guadalajara y el Atlas (Gómez, 1997: 17-18; Pliego, 2006: 23).
} 
Éste no es el espacio idóneo para tratar la riqueza histórica de tal fenómeno. De manera breve, mencionaremos algunos datos acerca de los orígenes y trayectoria de ambos equipos. El Club Guadalajara fue fundado en el año 1906 por un grupo de empresarios y empleados avecindados en la ciudad, de nacionalidades diversas - francesa, belga, austriaca y mexicana-, mientras que el Atlas nació diez años más tarde a iniciativa de varios jóvenes tapatíos de clase alta, quienes aprendieron a jugar futbol durante sus estancias como estudiantes en Inglaterra. Con los años, el Guadalajara se convirtió en uno de los equipos más populares a nivel nacional, en especial por la política de no contratar jugadores extranjeros y por ser el equipo con más títulos de campeón de liga en la primera división del futbol mexicano, un total de once, siete de ellos conseguidos entre 1956 y 1965 (la época del Campeonísimo), y los restantes en 1970, 1987, 1997 y 2006. Por su parte, los rojinegros del Atlas obtuvieron su único campeonato de liga en 1951. A pesar de ser un equipo poco ganador, el Atlas cuenta con un gran número de aficionados a nivel local, especialmente por su estilo de jugar al futbol, tradicionalmente conocido como académico o juego bonito, es decir, un futbol refinado, técnico, ofensivo y de toques rápidos, muy atractivo para la tribuna ${ }^{3}$.

Hablar de grupos de apoyo en el futbol nos remite a las tradicionales porras y a las nuevas barras. Posteriormente, en el desarrollo de este artículo, se tratarán más profundamente sus diferencias. Como punto inicial para ubicar a estos grupos, se propone un cuadro en el que se muestran sus nombres, el tipo de colectivo, su año de fundación y el número de miembros con que cuenta cada uno. Los cuadros anteriores arrojan datos interesantes. Por un lado se puede observar que, generalmente, los grupos más antiguos son los que se identifican con el estilo de apoyo de una porra y sus nombres se acercan a los territorios de la oficialidad reconocida por el club, así co-

\footnotetext{
${ }^{3}$ La historia del futbol en Guadalajara es muy rica en datos y anécdotas. Para una profundización en este tema, véase: Doñán, 2001; Gómez, 1997; Nuño y González, 1991; Pliego, 2006; Sotelo, 1999. Para la significación del Club Guadalajara en la integración de la identidad nacional, véase Fábregas, 2001
}

\section{Grupos de apoyo del equipo Guadalajara en la ciudad} de Guadalajara en 2006

\begin{tabular}{|c|c|c|c|}
\hline Nombre & Tipo & $\begin{array}{c}\text { Año } \\
\text { de fundación }\end{array}$ & $\begin{array}{c}\text { Número } \\
\text { de miembros }\end{array}$ \\
\hline $\begin{array}{l}\text { Porra } \\
\text { Popular } \\
\text { Guadalajara }\end{array}$ & Porra & 1953 & 60 \\
\hline $\begin{array}{l}\text { Porra } \\
\text { Femenil }\end{array}$ & Porra & 1984 & 30 \\
\hline Chiva Alegre & Porra & 1985 & 300 \\
\hline Chiva Amigo & Porra & 1989 & 80 \\
\hline $\begin{array}{l}\text { Porra } \\
\text { Oficial } \\
\text { Guadalajara }\end{array}$ & Porra & 1996 & 70 \\
\hline Legión 1908 & Barra & 1997 & 700 \\
\hline Irreverente & Barra & 2000 & 450 \\
\hline $\begin{array}{l}\text { Estirpe } \\
\text { Sagrada }\end{array}$ & Barra & 2002 & 130 \\
\hline Resistencia & Barra & 2002 & 120 \\
\hline $\begin{array}{l}\text { Chivas } \\
\text { de Corazón }\end{array}$ & Porra & 2004 & 200 \\
\hline
\end{tabular}

\begin{tabular}{l|c|c|c}
\multicolumn{5}{c}{$\begin{array}{c}\text { Grupos de apoyo del equipo Atlas en la ciudad } \\
\text { de Guadalajara en 2006 }\end{array}$} \\
\hline \multicolumn{1}{c}{ Nombre } & Tipo & $\begin{array}{c}\text { Año de } \\
\text { fundación }\end{array}$ & $\begin{array}{c}\text { Número de } \\
\text { miembros }\end{array}$ \\
\hline $\begin{array}{l}\text { Porra } \\
\text { Oficial Atlas }\end{array}$ & Porra & 1960 & 120 \\
\hline $\begin{array}{l}\text { Porra } \\
\text { Familiar }\end{array}$ & Porra & 1990 & 120 \\
\hline Barra 51 & Barra & 1997 & 120 \\
\hline La Calavera & Barra & 1999 & 120 \\
\hline $\begin{array}{l}\text { Forza } \\
\text { Rojinegra }\end{array}$ & Barra & 1999 & 120 \\
\hline $\begin{array}{l}\text { Pasión } \\
\text { Rojinegra }\end{array}$ & Barra & 2001 & 120 \\
\hline $\begin{array}{l}\text { Frente } \\
\text { Rojinegro }\end{array}$ & Barra & 2004 & 120 \\
\hline
\end{tabular}

Fuente: Elaboración propia. 
mo a su composición de carácter familiar. Las que se autodenominan barras expresan un carácter más combativo y apasionado, y su aparición en el escenario futbolístico es más reciente. Por otro lado, se puede apreciar una tendencia al incremento en el número de miembros de las barras, mientras que las porras se van quedando poco a poco re-zagadas en este renglón. Asimismo, cabe señalar que existen grupos recientes que parecen no tener muy clara su definición como barra o porra, al grado de proponer, a través de sus líderes, una clasificación que queda entre ambos estilos de apoyo. Lo cierto es que, por lo observado en las tribunas, el estilo más practicado es el de la barra. También es justo advertir que los datos se obtuvieron de los líderes de los grupos y que, en el caso de los que apoyan a las Chivas, el número de miembros es muy aproximado, ya que no existe un límite de personas que pueden ser registradas y no todas las que lo están asisten a todos los partidos. Por su parte, el número de miembros de los grupos rojinegros es el máximo que se puede registrar; sin embargo, con frecuencia esta cantidad es superada por la adhesión de individuos que, atraídos por su estilo de animación, se integran a ellos para nutrir el apoyo. Es decir, existen muchos barristas de hecho pero no de derecho. Procederemos ahora a tratar otros aspectos de la afición y la formación de los grupos.

\section{“OLÉ, OLÉ, OLÉ, CADA díA TE QUIERO MÁS...": EL ORIGEN DE UN SENTIMIENTO INDIVIDUALY COLECTIVO}

Jugar al futbol es una actividad muy extendida entre los niños y jóvenes tapatíos. Aficionarse a este deporte, no sólo como una práctica en la que los jóvenes intervienen activamente, sino como una pasión compartida por un equipo en particular, es un ingrediente común de la dinámica sociocultural de Guadalajara.

La mayoría de los aficionados del Atlas y del Guadalajara, principales equipos tapatíos en el circuito de la Primera División de la Federación Mexicana de Futbol, A. C., remiten a su niñez el origen de su opción por uno de los dos clubes. En este proceso convergen diferentes mediaciones: la herencia familiar, la socialización en el barrio y la escuela, la difusión del deporte a través de los medios de comunicación.

Los líderes de barras y porras del Atlas y del Guadalajara entrevistados coinciden en afirmar que su amor por los colores que actualmente apoyan y defienden se originó en la primera década de su vida. Sin embargo, no todos otorgan una importancia fundamental a la influencia familiar. Por ejemplo, Luis Felipe, líder de la Legión 1908, barra que apoya al equipo de las Chivas rayadas del Guadalajara, comenta:

No sé, nadie me lo inculcó en mi casa, no puedo decir que mi papá o mi mamá eran grandes aficionados a las Chivas; igual sí, sí se sienten aficionados a las Chivas, pero no, nunca fue en el caso de ellos que me llevaran al estadio a ver a Chivas o algo porque se hubiera dado esta afición ${ }^{4}$.

En este mismo tenor, Luis Jorge, líder de la Barra Calavera del Atlas, asegura que "no hubo nadie que me indicara que esto es futbol y no, simplemente me nació" 5 . En ambos casos, los informantes centran la poca o nula influencia familiar en la falta de acompañamiento de sus padres al estadio de futbol, es decir, enfatizan una carencia de acercamiento al futbol a través de sus padres, especialmente en su ausencia para presenciar partidos en vivo en el Estadio Jalisco.

Por el contrario, están aquellos que sí se sienten herederos de una tradición familiar futbolera, sobre todo de sus padres. Candelario, representante del Frente Rojinegro, afirma que su afición por el Atlas nació "desde niño. Mi papá me llevaba al estadio"6. A su vez, Fernando, fundador de la Barra 51 del Atlas, subraya que el origen de su pasión rojinegra "data de mucho tiempo [...] de familia [...] prácticamente de nacimiento $[\ldots]$ con empezar a ir al estadio con mi papá y ver a este equipo, y es algo que te marca y se te mete muy adentro"7. Como puede observarse, la

\footnotetext{
${ }^{4}$ Entrevista con Luis Felipe Martínez, realizada por Rodolfo Aceves el 6 de octubre de 2005 en Guadalajara, Jalisco.

${ }^{5}$ Entrevista con Luis Jorge García, realizada por Rodolfo Aceves el 27 de septiembre de 2005 en Guadalajara, Jalisco.

${ }^{6}$ Entrevista con Candelario Chávez, realizada por Rodolfo Aceves el 30 de septiembre de 2005 en Guadalajara, Jalisco.

${ }^{7}$ Entrevista con Fernando Moncada, realizada por Rodolfo Aceves el 20 de octubre de 2005 en Guadalajara, Jalisco.
} 
tradición familiar se reforzó con la asistencia de los informantes al estadio, acompañados por sus padres, para observar los partidos de su equipo favorito, es decir, la herencia es un elemento que se complementa con otros, como la asistencia al rito futbolero, para nutrir el proceso de conformación de la afición por un equipo.

Pero no sólo la familia tiene que ver en el nacimiento y desarrollo de una afición. También la interacción en distintos ámbitos interviene en este proceso. El barrio y la escuela son dos espacios en los que se practica la famosa cascarita, modalidad informal del futbol, con variaciones en el número de jugadores y en la aplicación de las normas, de acuerdo con las circunstancias y el lugar donde se juegue. Así, tanto en la calle como en el parque o en el patio del recreo, la cascarita facilita el acercamiento al mundo futbolero y nutre la imaginación de aquellos que encarnan a sus ídolos. Efraín Flores, entonces coordinador de Fuerzas Básicas del Club Guadalajara, menciona que adquirió su gusto por el futbol:

del barrio, del clásico barrio, de la escuela, [... siempre en el barrio jugábamos diario la cascarita y bueno, pues ahí se adquirió [...] el gusto por el futbol y esto, porque todavía lo tengo ese gusto, todavía lo sigo teniendo, como cuando empecé a los seis años ${ }^{8}$.

Además del juego, la asistencia a los partidos de futbol en el estadio con los amigos del barrio y los compañeros de la escuela propicia la socialización y el reforzamiento de la afición individual y colectiva. Candelario se refiere a este proceso cuando señala que su padre dejó de ir al estadio y "yo me iba con un amigo, ya ahí de poco a poco comenzamos a juntarnos pues varios chavitos del barrio y así, poco a poco empezamos a ir a cada partido al estadio"'. Paulatinamente, en el caso de Candelario, su grupo de vecinos, y algunos de otros barrios del norte de la zona metropolitana de Guadalajara darían forma al Frente Rojinegro.

Una característica central del futbol de nuestros días es su gran mediatización. Diariamente, a través de todos los

\footnotetext{
${ }^{8}$ Entrevista con Efraín Flores, realizada por Rodolfo Aceves el 5 de diciembre de 2005 en Guadalajara, Jalisco.

${ }^{9}$ Entrevista con Candelario Chávez, realizada por Rodolfo Aceves el 30 de septiembre de 2005 en Guadalajara, Jalisco.
}

medios electrónicos e impresos, somos testigos de una avalancha de información detallada sobre jugadores, equipos y competencias. La mayoría de los entrevistados comparte el hábito de escuchar los programas especializados de la radio. Inclusive, para uno de ellos, Luis Jorge, la radio fue el motor de inicio de su afición futbolera. A raíz del divorcio de sus padres y siendo hijo único, encontró en la radio su medio de contacto con el mundo del futbol y su afición por el Atlas:

ahí en tu pobre casa en ese tiempo no había ni tele, ¿sî́?, no había nada, eh, la afición comenzó por medio del radio [...] te puedo decir que lo sabía todo por el radio y, este, y pues te voy a ser sincero, por decir oía que ganaba Chivas y que perdíamos nosotros, por decir, decía bueno, feliz, ganaron Chivas, ¿por qué?, porque me inclinaba a los dos. Después de un partido que a Chivas le ayudaron según ahí los comentaristas, pues, de la radio, porque pues yo no, que le ayudaron y nos ganaron cinco dos, por ahí así, y tres penales le habían marcado a Chivas y que no habían sido, desde ahí comenzó el rencor sobre las Chivas. Nada de que ya 'qué bueno que ganaron las Chivas' ya como consuelo, no, ya no, ahí era de que le agarré desde ahí un odio a Chivas y comenzó la afición, ahora sí fuerte, sobre los rojinegros ${ }^{10}$.

La familia, el barrio, la escuela, los medios. Todos estos factores integran un proceso que genera y forja la pasión por una camiseta, por unos colores, por una filosofía y un estilo de juego. Una pasión que se asocia a la vida diaria de los aficionados al futbol, de los seguidores de un equipo. Una pasión que se comparte con otros seguidores del mismo conjunto y encuentra una expresión colectiva cada quince días en el Estadio Jalisco, cuando las Chivas o los rojinegros reciben a sus contrincantes deportivos. Una pasión que trasciende al individuo para formar un "nosotros".

\section{De las porras a las barras}

El surgimiento en México de los grupos de apoyo denominados barras data de la década de 1990. Heredan su

${ }^{10}$ Entrevista con Luis Jorge García, realizada por Rodolfo Aceves el 27 de septiembre de 2005 en Guadalajara, Jalisco. 
nombre y sus prácticas de las famosas barras bravas sudamericanas, especialmente las argentinas, caracterizadas por el ferviente e incondicional apoyo que ofrecen a sus equipos durante todo el partido, mediante saltos y movimientos rítmicos del brazo y la mano derecha hacia delante y hacia atrás, cánticos (para alentar a su equipo o insultar al contrario), gritos (de apoyo o denuesto), emblemas y vestimenta (con los colores y símbolos de su equipo). Estas prácticas, asociadas con la apropiación de un espacio físico determinado, es decir, con un lugar asignado para su distribución en los estadios, llaman poderosamente la atención del resto del público, dada la intensidad y la vistosidad con que son ejecutadas. Sus miembros no se sientan durante el desarrollo de los partidos, independientemente de las condiciones naturales y materiales del entorno, y provienen de los más variados estratos socioeconómicos, edades y género, aunque en su mayoría son hombres jóvenes entre los trece y los veinte años de edad, de clases media y baja. En muchas ocasiones, las manifestaciones de violencia dentro y fuera de los estadios de futbol se relacionan con ellos.

116 La primera barra que se fundó en nuestro país fue la Ultra Tuza, grupo de apoyo del Club Pachuca, cuya directiva:

contrató a cuatro elementos, jefes de sus barras: Jorge Díaz Paredes y Eduardo González de la Católica de Chile; Federico Pérez y Alex Fernández del Saprissa de Costa Rica. La idea era tener apoyo incondicional de las porras los $90 \mathrm{mi}-$ nutos, con cánticos y sin violencia. Cuando la Barra Ultra Tuza se presentó en sociedad, causó tal impresión que varios equipos decidieron crear sus propias barras (Calderón Cardoso, 2001: 70).

La Ultra Tuza apareció en 1996, en un partido del Torneo de Copa entre el Pachuca y el América ${ }^{11}$. En Guadalajara, la primera fue la Barra 51, del Club Atlas. Este grupo, que comenzó sus actividades con cerca de diez miembros, creció rápidamente sumando un buen número de integrantes en un corto periodo. Su nacimiento tuvo lugar en el mes de agosto del año 1997, en el marco de una etapa de "argentinización" del Atlas (contra-

\footnotetext{
$11<$ http://www.pasiontuza.com>.
}

tación de directores técnicos y jugadores argentinos, tanto para el primer equipo como para la organización de la estructura de fuerzas básicas). En un breve lapso, la 51 superó con mucho a los grupos de corte tradicional conocidos como porras, entre ellas a la Porra Oficial y a la Porra Familiar, que ya contaban con experiencia de muchos años en las actividades de apoyo al equipo rojinegro. La Barra 51 adquirió una importancia tal que, ayudada por las disposiciones oficiales de concentrar a los diferentes grupos de apoyo en la planta baja norte del Estadio Jalisco por razones de seguridad y control, pareció absorber a las demás agrupaciones de tipo tradicional y contagiarlas de sus prácticas, hasta el punto de que el "chiquitibum" y el "Atlas ra, ra, ra" fueron cediendo su lugar a los cánticos que se ejecutan durante todo un partido.

Poco después del surgimiento de la Barra 51, el Club Guadalajara tuvo su primera barra: la Legión 1908. Al igual que la 51, el impacto de sus prácticas se extendió hacia los demás grupos de apoyo, a excepción de la Porra Oficial Guadalajara, la cual todavía se sitúa en la zona preferente oriente, y la Porra Popular Guadalajara, con ubicación en la preferente poniente, muy distantes de la A norte, lugar destinado a la Legión y demás agrupaciones.

La fundación de los grupos llamados barras, tanto para atlistas como para rojiblancos, tuvo que ver con dos factores principales: primero, la voluntad de ciertos aficionados que se reunieron para constituirse como tales y, segundo, el interés de las directivas de los clubes por asegurar un apoyo continuo a sus equipos, partido a partido. La iniciativa de un grupo de jóvenes rojinegros de reunirse y alentar al equipo de sus amores dio origen a la Barra 51. Según uno de sus fundadores, esta barra:

nació muy espontáneo, fue algo muy espontáneo, muy natural, nace de ir siempre al estadio un grupo de amigos y sentir la necesidad de apoyar a este equipo de una manera diferente a como se hacía anteriormente. Así fue como nació y eso nos motivó a formar un grupo sin nombre al principio, un grupo de amigos que se juntaban a apoyar al Atlas de una manera diferente a la anterior, saltando, cantando, brincando en todo momento y apoyando en todo momento al equipo y entregándosele de una manera más fuerte ${ }^{12}$.

12 Entrevista con Fernando Moncada, realizada por Rodolfo Aceves el 20 de octubre de 2005 en Guadalajara, Jalisco. 


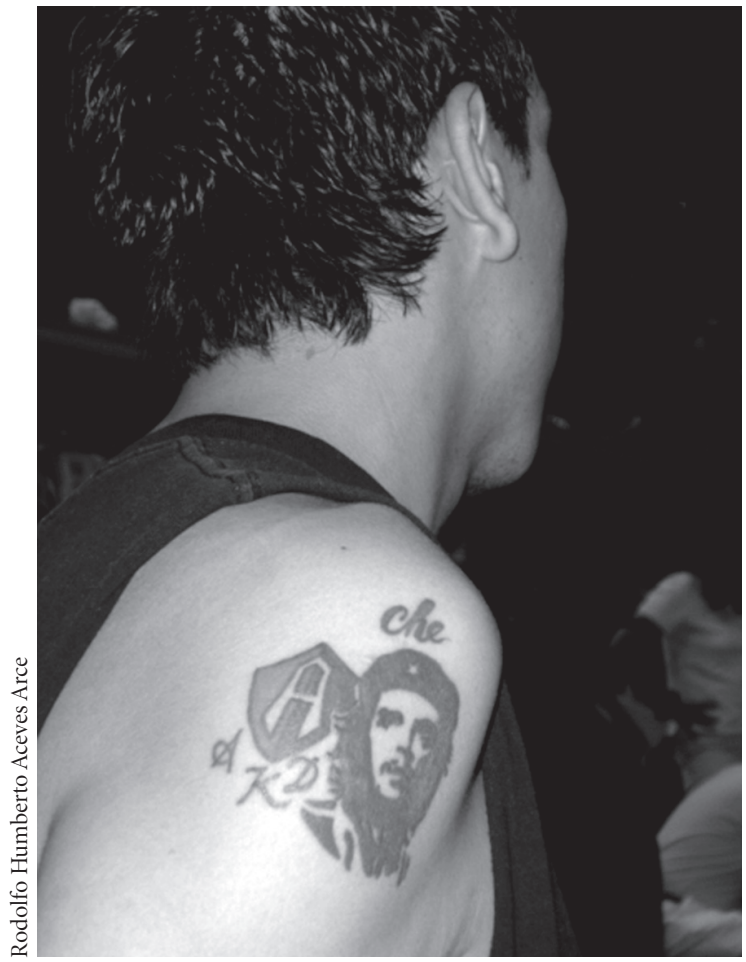

Aficionado en el partido Atlas vs. Jaguares, 24 de septiembre de 2005.

Según cuenta Luis Felipe, uno de los fundadores de la Legión 1908, grupo de apoyo de las Chivas, la inquietud por formar una barra rojiblanca también surgió de varios jóvenes que compartían su afición por el Guadalajara. Él reconoce el impacto mediático en la reproducción de las prácticas asociadas a este tipo de agrupaciones:

la idea surgió por allá en el año 97, precisamente el año en el que fueron campeones, fue entre varios chavos [...] todo surgió a raíz de [...] yo creo que lo que tuvo gran influencia en nosotros fue el popularizarse y la transmisión de los partidos por cable de la liga argentina, o sea el ver los partidos de Boca o de River o Racing o todos estos equipos grandes de Argentina por televisión, ver la forma en que alentaban, la forma en cómo se hacía el partido, pues era una forma que contagia, o sea, uno véía aquí en los partidos completamente callado el estadio cuando, no sé, muy de vez en cuando, de repente gritan "Chivas, Chivas", que sí es un grito que todavía sigue estando vigente y que sigue emocionando a la gente y a nosotros también, pero era lo único, entonces todo lo demás, el rato callado y ya, y de repente ver estos partidos y ver cómo, cómo se sentía la pasión, pasión que nosotros sentíamos que teníamos también, entonces fue así cuando, pues, poco a poquito nos fuimos juntando y como que no fue la idea nada más de uno porque de repente veíamos un grupito a un lado y luego un grupito en otro y llegábamos y les preguntábamos: "y no ustedes que no, pos queremos hacer una barra y todo eso", "ah pos hay que juntarnos"13.

Además de dar importancia a la espontaneidad o naturalidad que caracterizó el inicio de estos grupos, los informantes subrayan la diferencia de sus prácticas respecto de los característicos gritos "Chivas, Chivas" o "Atlas, Atlas", la cual es decisiva para entender cómo los grupos de apoyo hasta entonces más tradicionales — las porras oficiales o familiares, que se distinguían también por el carácter de su composición más cercana a lo familiar y al compadrazgo, además de que sus miembros se consideran de mayor edad que los barristas - fueron tomando distancia de las barras o, por el contrario, se integraron con reservas al empuje de estos nuevos grupos, en una especie de cumplimiento del dicho "si no puedes con el otro, únetele" ${ }^{\prime 4}$. Asimismo, es significativo el reconocimiento de la influencia mediática, en especial de la televisión, para la adopción de estas formas de animación futbolera.

\section{Los nombres de las barras}

Asignar un nombre a la barra es producto de un consenso entre los fundadores de la misma. En este proceso se expresan diferentes formas de entender la afición e, incluso, la vida. En el caso de la Barra 51, el nombre surgió de la siguiente manera:

los amigos que nos habíamos juntado a iniciar esto, ahí nació la idea de ponerle algún nombre porque ya por ahí en los periódicos nos ponían nombres y nos daba de repente risa, ¿no?, entonces pues se optó por ponerle el nombre del año

\footnotetext{
${ }^{13}$ Entrevista con Luis Felipe Martínez, realizada por Rodolfo Aceves el 6 de octubre de 2005 en Guadalajara, Jalisco.

${ }^{14}$ El dicho popular originalmente dice: "si no puedes con el enemigo, únete a él". En el presente caso, se modifica el término "enemigo" por el de "otro".
} 
más glorioso de la institución, la Barra 51, en honor al título que se consiguió en aquel año y que es el único que tenemos ${ }^{15}$

Por su parte, el nombre de Legión 1908 se tomó de una de las fechas fundacionales del Club Guadalajara, también producto del consenso entre sus integrantes:

el primer nombre que a nosotros se nos ocurrió, pues no nos quebramos mucho la cabeza, ¿no? Había Barra Rojiblanca 1908 pues lo sometimos a votación, la idea era que fuera 1906, cuando fue el año de fundación del Club Guadalajara, bueno no como Club Guadalajara, sino como Club Unión; posteriormente, en el año 1908, cambia el nombre de Club Unión a Club Deportivo Guadalajara; entonces, bueno, se retomó esta fecha para ponerla como parte representativa de nuestro grupo, por ser precisamente la fecha en que tomó el nombre de la ciudad de Guadalajara ${ }^{16}$.

El nombre de otros grupos representa la forma de entenderse como ciudadanos, como miembros de una comunidad, o la intensidad de su pasión por su equipo. Así, tenemos que el Frente Rojinegro, formado principalmente por atlistas de la colonia Constitución, barrio del municipio de Zapopan al norte de la zona metropolitana de Guadalajara, de características eminentemente populares, responde a una tradición de labor social en la colonia, heredada de generaciones precedentes:

en la colonia, desde hace muchos años, ha habido un grupo, o sea, que ya se ha pasado por generaciones, un grupo de mismos vecinos que organizan conciertos, a lo mejor uno por año, a beneficio de orfanatorios, de asilos, de casas de indígenas; entonces pues ahorita nosotros estamos dentro de esa generación, pues, que nos gusta hacer labor social y pues siempre se manejó así, que éramos, que somos un frente común, entonces siempre se me quedó eso en la mente y ya, pues nosotros vamos a ser el Frente Rojinegro ${ }^{17}$.

\footnotetext{
15 Entrevista con Fernando Moncada, realizada por Rodolfo Aceves el 20 de octubre de 2005 en Guadalajara, Jalisco.

${ }^{16}$ Entrevista con Luis Felipe Martínez, realizada por Rodolfo Aceves el 6 de octubre de 2005 en Guadalajara, Jalisco.

${ }^{17}$ Entrevista con Candelario Chávez, realizada por Rodolfo Aceves el 30 de septiembre de 2005 en Guadalajara, Jalisco.
}

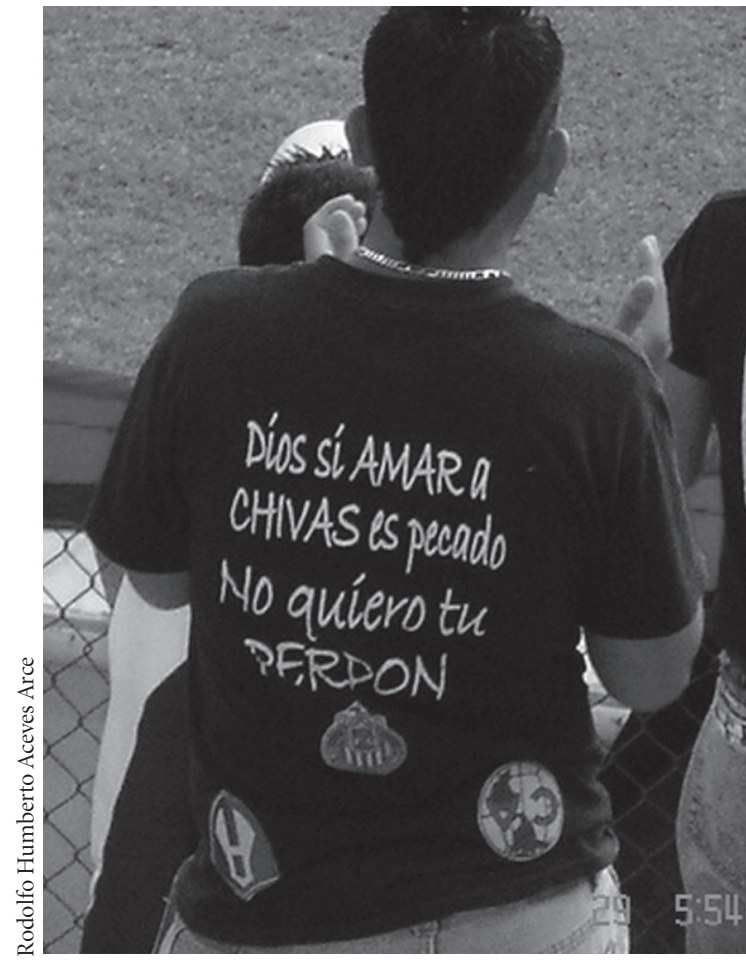

Aficionado en el partido Chivas vs. Morelia, 29 de octubre de 2005.

En el renglón de la fuerza de la pasión, la Barra Calavera intentó distinguirse de los demás grupos de apoyo reafirmando el carácter de su afición desde su nombre mismo:

así era como se llamaba primero, Furia Calavera [...], bueno, y la gente decía que nada más Calavera, se supone que calavera como ahí en lo del veneno y eso que dice peligro, ¿sí?, la otra, un mensaje o eslogan, no sé cómo decirte, es que, supuestamente, ni muertos dejaremos de ser rojinegros, entonces significa que hay un muerto que sigue siendo rojinegro $^{18}$.

El nombre que identifica a la barra marca el significado que para la vida de sus integrantes conlleva el ser aficionado a los rojinegros del Atlas. Aunque la calavera se identifique con la muerte, también representa lo que en vida

\footnotetext{
${ }^{18}$ Entrevista con Luis Jorge García, realizada por Rodolfo Aceves el 27 de septiembre de 2005 en Guadalajara, Jalisco.
} 
fueron sus seguidores, es decir, fieles a sus colores durante toda su existencia.

\section{ESTRUCTURA INTERNA, JERARQUÍAS Y FUNCIONES}

En cuanto a su organización interna, las barras de los equipos Atlas y Guadalajara se caracterizan por combinar aspectos de formalidad y de informalidad. Es decir, estos grupos no tienen una estructura ni una división de labores rígida, aunque sí demuestran tener un grado de organización de acuerdo con las necesidades del grupo y son comandadas por un líder, que en muchas ocasiones es también cofundador de la barra. De los integrantes de barras o porras que colaboraron como informantes en este estudio todos asumen el cargo de líder, dirigente o coordinador. Sólo en el caso de la Porra Oficial del Atlas, el actual líder no fue su fundador, aunque su esposa, quien desempeña funciones importantes dentro del grupo, sí lo es. Por su parte, Candelario, quien es coordinador del Frente Rojinegro, dice compartir el cargo con otra compañera. Sin embargo, tanto dentro como fuera del estadio es claro que él es el referente para los miembros y para los demás aficionados. Por otro lado, en el caso de la Barra 51, Fernando, cofundador, comenta que ya no es el líder de la misma, sino que sólo tiene labores de representación, que comparte con otro miembro del grupo, ante la directiva del club.

De acuerdo con la información obtenida, es claro que las barras asientan su liderazgo y representación en uno $o$ varios de sus miembros fundadores. No existe un mecanismo de elección de líderes, incluso varios de ellos argumentan que no existe esta figura, que la barra no es de nadie sino de todos sus integrantes, lo cual se asocia con la atracción que la ideología anarquista ejerce sobre algunos de ellos. Este fenómeno requiere un análisis más profundo, ya que, a priori, parece estar en un nivel puramente simbólico, expresado en el caso de la "A" de la anarquía en emblemas y vestimentas. De hecho, en el caso de los atlistas, este símbolo es utilizado como sustituto de la característica "A" del escudo rojinegro. Sin embargo, no todos los líderes comparten esta ideología. Algunos de ellos tienen una conciencia política limitada, restringida al papel de electores en los comicios locales, estatales $\mathrm{y}$ federales.

Podemos distinguir claramente la cabeza del grupo, representada por uno o varios líderes o coordinadores. Éstos se apoyan en algunos miembros de su confianza para delegar labores de organización y de tesorería, y son los elementos son los más visibles en la asignación de funciones de una barra. Las actividades de un líder de barra se centran en la representación de los miembros del grupo ante la directiva del club. El líder es el responsable de cuidar el comportamiento de los barristas, de recoger en el club los boletos de entrada a los partidos, de cobrarlos y entregarlos a los miembros de su grupo, de coordinar las labores de organización de viajes a otras ciudades, de delegar tareas a otros integrantes de la barra, y de organizar actividades paralelas a las de apoyo al equipo, tales como conciertos, celebraciones, manifestaciones públicas, servicios sociales, asistencia a reuniones con directivas, otros grupos y autoridades civiles.

La participación de los miembros no líderes en las barras se restringe a actividades de logística antes y después de los partidos de futbol, así como dentro y fuera del estadio. Gran parte de éstas son actividades auxiliares a las del líder: ayuda en el registro de asistencias en los partidos, cobranza de los boletos de entrada, cobranza de las cuotas en el caso de viajes a otras ciudades, vigilancia del comportamiento de los barristas fuera y dentro del estadio custodia, transporte, colocación y retiro de mantas (también llamadas trapos), los alambrados del estadio, portación y toque de bombos y tambores, propuesta de cánticos, acompañamiento al líder en reuniones con directivas, grupos de apoyo y autoridades civiles, entre otras. En algunos casos, estas tareas se asignan a personas de confianza del líder, unos familiares, otros amigos, con cierta flexibilidad dadas las circunstancias personales y laborales de los miembros responsables. En tal tenor, Sabritas, líder y fundador de la Estirpe sagrada de las Chivas, comenta que:

mi esposa generalmente es la persona que se encarga de cobrar y de vender los boletos [...] Jaime Ávila es un muy buen cuate y el Monje también, generalmente me ayudan a [...] las tareas de [...] ir a recoger los boletos, ir a traerlos, cuando hay viajes también me ayudan a coordinarlos $[. .$. 


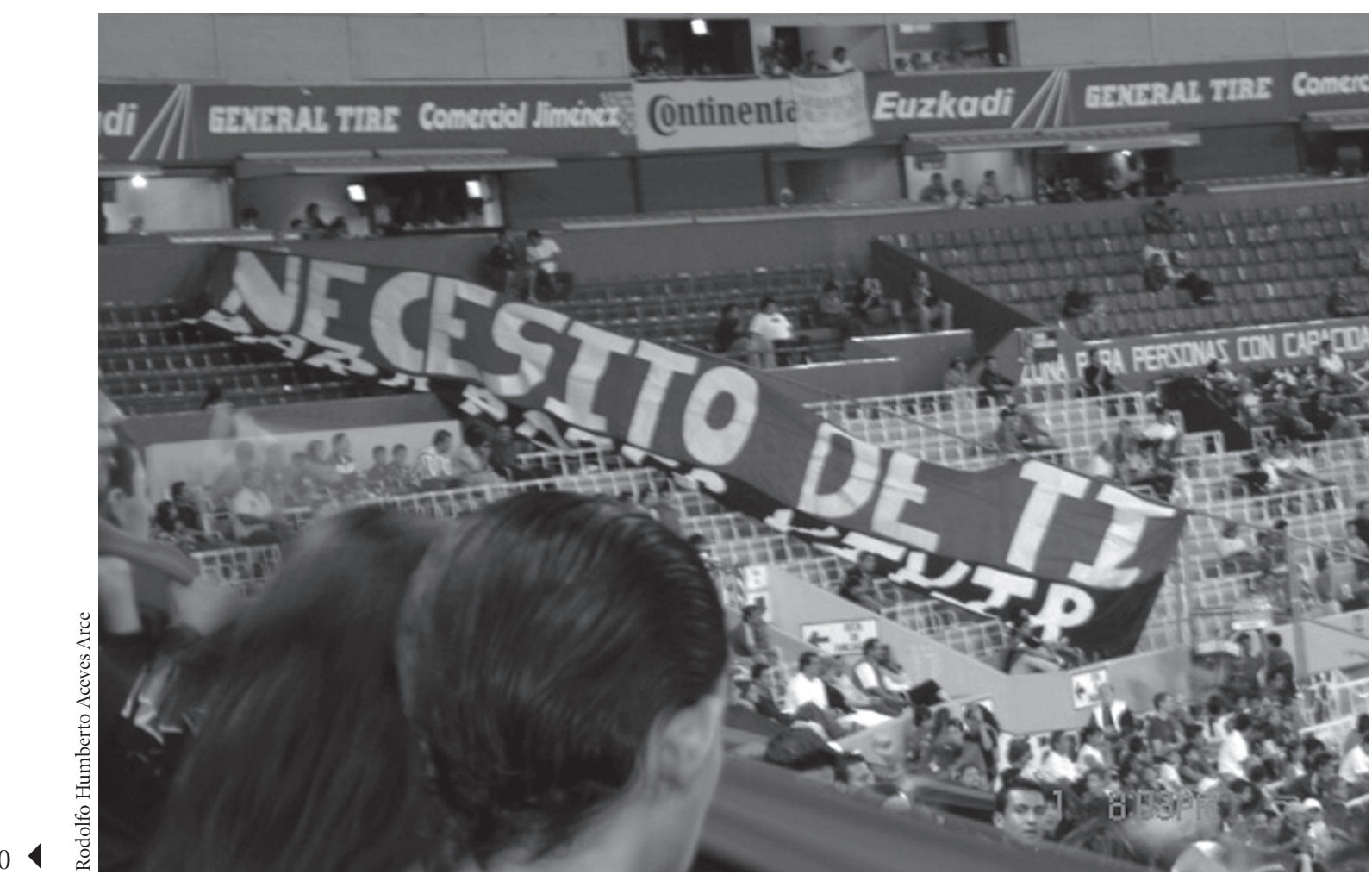

Las tribunas en el partido Atlas vs. Atlante, 1 de octubre de 2005.

pero fijate que anteriormente estaba mucho más delimitado las funciones, actualmente, la gente con la que me he rodeado ha cambiado un poco los roles de su vida, entonces [...] el Monje anteriormente era [...] activista 100\%, él me ayudó a [...] hacer una ideología de la barra, hicimos un librito con un $[. .$.$] decálogo, con objetivos, con una visión, con una$ misión [...] del grupo y para mí fue muy importante, pero él $[\ldots]$ ya es artista el cabrón y [...] entre la ópera y [...] los estudios pos [...] ya no mete la mano como antes ${ }^{19}$.

\section{MEMBRESÍA}

El primer y fundamental requisito para ser miembro de una barra es compartir la afición, el amor, la pasión por un equipo, por unos colores, por una tradición. Es decir,

\footnotetext{
${ }^{19}$ Entrevista con Sabritas, realizada por Rodolfo Aceves el 19 de noviembre de 2005 en Guadalajara, Jalisco.
}

la subjetividad de un aficionado se entrelaza con la de otros para formar una comunidad, un nosotros. Sin embargo, las autoridades civiles y las directivas de los clubes establecen ciertos requisitos para que estos grupos puedan afiliarse y ejercer algunas prerrogativas. Así, cada miembro de una barra o porra debe entregar al líder, al empezar cada torneo, dos fotografías y copias fotostáticas de identificación y comprobante de domicilio. De estos documentos se prepara un archivo que resguarda el club y otro que se queda en manos del líder de la barra. Con las fotografías se elabora una credencial que cada barrista debe mostrar y entregar con su boleto de entrada al ingresar al estadio, la cual lo acredita como integrante de la barra. En ella aparecen, además de su foto, su nombre y el del grupo al que pertenece, un número de registro y la vigencia de la membresía, que se renueva cada año. La credencial vuelve a sus manos antes de ingresar al estadio en un nuevo partido, durante la semana 
el líder recoge las credenciales en las instalaciones del club junto con el número de boletos que corresponde a sus afiliados.

Los boletos de entrada también se encuentran marcados con una leyenda que indica que corresponden a miembros de las porras o barras. El club entrega boletos foliados a cada representante, quien, una vez que los cobra y los da a sus representados, debe liquidar sus cuentas con un empleado del club en el estadio: entrega al funcionario el dinero recaudado y los boletos no vendidos. Para los miembros de estos grupos, el costo de las entradas tiene un descuento especial: en el caso del Atlas, el precio para la zona A norte es de 80 pesos, pero para los afiliados es de 50 pesos. En cuanto a las Chivas, el precio de la misma zona es de 150 pesos y para los barristas es de 70 pesos. Adicionalmente, algunos líderes cobran 10 o 20 pesos extra por cada boleto para financiar gastos relativos a la barra, como adquisición y elaboración de mantas, compra de materiales como papel y pinturas, banderas, organización de fiestas, conciertos, etcétera.

\section{Composición por género, edad y clase social}

En el imaginario colectivo tapatío, los aficionados del Guadalajara y del Atlas se diferencian socialmente. Son frecuentes las bromas, generalmente para ridiculizar al contrario, que marcan la distinción entre los chivistas y los rojinegros. Como ejemplos tenemos las siguientes:

- ¿Por qué es posible encontrar estacionamiento afuera del estadio cuando juegan las Chivas? Porque sus aficionados no tienen auto, van en bicicleta o en camión.

- ¿Por qué nieva dentro del estadio cuando anotan un gol las Chivas? Por la cal que se desprende de sus manos al aplaudir la anotación (aludiendo a que son albañiles).

—Los sábados por la noche, cuando juega el Atlas, en las calles aledañas al estadio sólo ves estacionados Mercedes y BMW.

La historia de esta diferenciación social se remonta a las décadas de 1940 y 1950, cuando ambos equipos jugaban en el Campo Oro, al oriente de la ciudad de Guadalajara, y sus aficiones se distribuían en las distintas localidades del graderío. Los atlistas se situaban en la zona de sombra y al centro de la cancha, es decir, la mejor y más cara sección de las tribunas, además de que asistían vestidos formalmente y se comportaban de una manera más seria y respetuosa, mientras que los del Guadalajara se sentaban en la zona popular, más económica, y se comportaban de una manera ruidosa y escandalosa, ya que llevaban banda y bailaban entre $s^{20}$.

Actualmente las cosas han cambiado. Al igual que el universo de los aficionados tapatíos, en cuanto a su composición, la barra es un grupo complejo, heterogéneo, en el que interactúan individuos de los más diversos orígenes socioeconómicos, de edades y de género. Las mujeres son cada vez más participativas, tanto en número como en la intensidad de sus acciones dentro y fuera de la cancha. $\mathrm{Al}-$ gunas son líderes, otras tienen importantes tareas al interior del grupo y muchas más gritan, cantan, alientan y ofenden vehementemente. Sin embargo, a pesar de su creciente inclusión, el futbol sigue siendo un espacio mayoritariamente masculino. Así, según la información proporcionada por los líderes de los grupos y corroborada por funcionarios de los clubes, las barras están formadas entre 70 y $80 \%$ de hombres y entre 30 y $20 \%$ de mujeres ${ }^{21}$.

En lo referente a las edades, predominan los jóvenes entre los 14 y los 20 años de edad. A decir de Chava Magaña, líder de la Irreverente del Guadalajara, "la edad oscila entre los 14 y 21 años, es la media de las personas que integran la barra" 22 . No obstante, pueden observarse me-

\footnotetext{
${ }^{20}$ Entrevistas realizadas con Rodolfo Medina Villaseñor el 9 de noviembre de 2005 y José Dorazco el 14 de noviembre de 2005 por Rodolfo Aceves en Guadalajara, Jalisco.

${ }^{21}$ Las cifras obtenidas son aproximadas, resultado de la observación del investigador y de la información proporcionada por los miembros de las barras y los funcionarios de los clubes, quienes tienden a "cerrar" los números y los porcentajes para dar una idea general, pero al mismo tiempo real, de la composición de los grupos. Lo mismo puede decirse en el caso de la diversidad de edades y de orígenes socioeconómicos. Cabe agregar que los clubes manejan bases de datos de los colectivos de aficionados que se afilian al club, pero de manera confidencial. Además de los nombres de los integrantes, entre otros datos, se especifican domicilios y edades, lo cual proporcionaría una imagen sociodemográfica y generacional muy rica de estos grupos. Sin embargo, no se pudo tener acceso a dichas bases de datos. ${ }^{22}$ Entrevista con Chava Magaña, realizada por Rodolfo Aceves el 19 de octubre de 2005 en Guadalajara, Jalisco.
} 
nores de entre siete y 13 años y una buena cantidad de personas entre los 20 y los 30 años, así como, en menor medida, otros que van desde los 40 hasta los 70 años de edad.

En lo relativo al origen socioeconómico de los barristas, la gran mayoría son de clase media baja y baja, provenientes de barrios y colonias humildes, estudiantes y trabajadores. Sin embargo, también pueden encontrarse miembros de las clases media alta y alta, estudiantes, profesionistas y empleados, residentes de fraccionamientos exclusivos de la ciudad. En especial, la Barra 51 del Atlas fue fundada por un grupo de amigos de sectores acomodados, algunos de los cuales tuvieron el contacto directo con las prácticas de las barras argentinas en la ciudad de Buenos Aires. Respecto de la composición socioeconómica de su grupo, Fernando, fundador de la 51, confirma que:

ves de todo. Ves desde gente de [...] lana o de mucha lana hasta $[\ldots]$ chavos $[\ldots]$ que no pueden pagarse ni siquiera un boleto, que realmente se las ven duras para [...] lo básico en la vida, obviamente durísimo para ir a [...] pagar un boleto al estadio ${ }^{23}$.

\section{Derechos y obligaciones}

Ser miembro de una barra o porra implica tener derechos y obligaciones. Entre los primeros están el tener asegurado el boleto de entrada a todos los partidos de su equipo como local y a un costo preferencial. Como contrapartida, el barrista tiene la obligación moral de asistir a todos los partidos y apoyar a su equipo incondicionalmente durante todo el cotejo deportivo, así como de comportarse correctamente dentro y fuera del estadio, antes y después de los partidos, evitando actos de violencia y de corrupción, tales como la reventa.

Ahora bien, el número de afiliados y, por lo tanto, de boletos de entrada, está limitado a 120 por cada barra atlista y, en el caso de las rojiblancas no hay límites en

\footnotetext{
${ }^{23}$ Entrevista con Fernando Moncada, realizada por Rodolfo Aceves el 20 de octubre de 2005 en Guadalajara, Jalisco.
}

cuanto a número, sólo en los periodos para registrar a sus miembros, sea por renovación o de nuevo ingreso. De esta manera, el número de boletos que se asigna a las barras rojiblancas obedece a un promedio de asistentes que se establece entre el club y el líder del grupo. Es decir, los clubes sólo aceptan un número máximo de miembros, de acuerdo con criterios de control, cupo en el espacio asignado a las barras y promedio de asistencia ${ }^{24}$. Por tal motivo, la membresía es un aspecto que debe cuidarse, dado que hay gente que quiere participar en las barras y espera a que un lugar se desocupe. Es posible perder la afiliación por presentar comportamientos violentos o ilegales, como provocar o participar en peleas contra otros aficionados o, incluso, miembros del mismo grupo, dentro o fuera del estadio, o revender boletos para un partido. También se puede perder por no asistir a apoyar al equipo, se han presentado casos en que algunos aficionados sólo se afilian para asegurar su entrada a partidos importantes, como los clásicos o los juegos contra equipos muy populares.

La membresía, con todos sus requisitos y los derechos y obligaciones que implica, ha funcionado como un mecanismo de control de la conducta de los barristas y porristas. A través de la credencialización, es posible para las autoridades civiles y para las directivas de los equipos tener identificados a todos los miembros de los grupos de apoyo, especialmente a los más violentos, quienes pueden ser expulsados de las barras y porras. Sin embargo, la medida de la expulsión de los sujetos violentos no implica que no vuelvan a entrar a los estadios en calidad de aficionados no afiliados a los grupos, por lo que la efectividad de esta medida debe ser cuestionada y seriamente evaluada. También hay que tomar en cuenta que se han dado casos de falsificación de credenciales o duplicación de registros con datos no verdaderos, hecho que muestra que esta normatividad puede ser burlada con cierta facilidad.

\footnotetext{
${ }^{24}$ En el caso del número total de afiliados a las barras y porras atlistas, los líderes comentan que existen aproximadamente 800, mientras que en el caso de los del Guadalajara se habla de 1500 sólo en la ciudad de Guadalajara. Es muy difícil que los barristas y porristas asistan a todos los partidos, razón por la cual se trata de establecer un promedio de asistencias para controlar el número de boletos que se asignan a cada grupo.
} 


\section{Socialización}

La barra es un grupo que fomenta la socialización entre sus miembros. A través de la interacción dentro y fuera del estadio, durante la semana o el día del partido, sus integrantes se relacionan continuamente. Para algunos, la barra es un espacio en el que pueden divertirse al tiempo que apoyan apasionadamente a su equipo. No en vano, cuando llega el día del partido, muchos de ellos dicen prepararse para una fiesta, para un carnaval. Chava Magaña, líder de la barra Irreverente, seguidora de las Chivas rayadas del Guadalajara, comenta:

Haz de cuenta que $[\ldots]$ a mí cada quince días me invitan a una fiesta, cada quince días voy a una boda, cada quince días voy a un bautizo, donde va a ver cerveza, baile, canto, diversión, borrachera, todo [...] para mí es una fiesta cada quince días ${ }^{25}$.

Algunos grupos viajan juntos, en camión, no sólo a otras plazas sino de sus barrios al Estadio Jalisco. Ahí comienza el convivio, el "desmadre". Fuera del estadio, los barristas platican, cantan, beben cerveza o refrescos, bailan. Ya dentro del estadio, cantando y saltando, la interacción se intensifica; incluso se hace difícil ver atentamente las jugadas de la cancha; más de uno se pierde un gol o un lance emocionante, pero parece no importar mientras se siga en el ambiente, apoyándose en el hombro del compañero y compartiendo sonrisas, bebidas, algún carrujo de marihuana y hasta los insultos a jugadores y aficionados del equipo contrario.

Fuera del estadio, al final de un partido ganado, se baila y se canta, máxime cuando se obtiene el triunfo contra los rivales más odiados. Se comparte más bebida y la fiesta puede alargarse hasta la madrugada en algún bar, en la casa, en la Minerva para el caso de los de Chivas o en la Glorieta de los Niños Héroes para los rojinegros. Si se pierde, la fiesta termina pronto, muchos sólo quieren irse a su casa a olvidar el partido, a llorar la derrota. La mayoría se

\footnotetext{
${ }^{25}$ Entrevista con Chava Magaña, realizada por Rodolfo Aceves el 19 de octubre de 2005 en Guadalajara, Jalisco.
}

retira a sus hogares, ya sea en el camión rentado, en el transporte público, en el auto propio o caminando.

Cuando no es día de partido, los espacios de socialización de la barra se pueden extender a la cuadra del barrio. En el caso del Frente Rojinegro, la convivencia se traslada al parque El Grillo, en la colonia Constitución, lugar donde los barristas juegan la cascarita entre ellos y contra otros grupos, incluso de policías del Ayuntamiento de Zapopan. La competencia también puede ser basquetbolera. El parque ha sido adornado con distintivos rojinegros, entre los que destacan los murales dedicados a Eduardo Berizzo, Julio César Gradito, Guillermo Rodríguez y Juan Carlos Medina. También se pueden observar los escudos del Atlas y los símbolos de la anarquía y de la barra en cuestión. Los jóvenes del Frente se reúnen en este espacio para cristalizar sus expresiones rojinegras en los muros del parque, para jugar y para tratar de mantener el parque limpio. También tienen proyectado pintar las bancas y columpios con el rojo y el negro. Ya por la noche se reúnen en una esquina cercana a la casa de su líder, Candelario, a seguir platicando. Además de la plática sobre futbol y sobre la vida en general, se discuten temas que tienen que ver con la labor social en el barrio, tales como la organización de conciertos a beneficio, la limpieza y el mantenimiento del parque, el apoyo a la gira del Ejército Zapatista de Liberación Nacional (EZLN) ${ }^{26}$, etcétera. Es decir, la socialización a partir del grupo de apoyo al equipo de futbol trasciende el ámbito meramente deportivo para acercarse al ámbito comunitario y político, aunque sea de manera limitada.

Para algunos miembros, la convivencia en las barras fortalece los lazos de amistad. Algunos de los entrevistados comentan que en este espacio han generado y fortalecido sus relaciones con otros barristas. Por ejemplo, Fernando, de la 51 del Atlas, afirma:

aquí ganamos muchos amigos [...] se puede decir que yo allí he encontrado grandes amigos, he hecho muy [...] bue-

\footnotetext{
${ }^{26}$ A través de las diversas pláticas sostenidas con Candelario, líder del Frente Rojinegro, pude percatarme de su interés por temas políticos nacionales y por la atracción que sobre él y otros miembros de la barra ejercen las ideas del Subcomandante Marcos y del Ejército Zapatista de Liberación Nacional.
} 
nos amigos, entrañables amigos [...] con los que me frecuento bastante fuera de [...] lo que es el estadio y [...] así pasa con muchos [...] prácticamente todos nos hicimos amigos ahí2 ${ }^{27}$.

\section{RELACIONES EXTERNAS}

A continuación se propone un abanico de relaciones hacia fuera del grupo, es decir, de las barras con otros actores sociales: las directivas de los clubes, los equipos de futbol, las barras de otros equipos, los aficionados no integrantes de barras, las autoridades civiles y los medios de comunicación. Con la finalidad de entender mejor el fenómeno de las barras, es necesario rastrear sus vínculos con los colectivos mencionados.

\section{Relaciones con las directivas}

La directiva está formada por los socios y funcionarios del club al que representa el equipo. Generalmente, las barras y gran parte de los aficionados consideran que las directivas no saben de futbol. Son hombres de negocios a los que sólo les interesa el deporte traducido en ganancias, en millones de dólares. Son los hombres de "pantalón largo" que acaban con los equipos, que no tienen conciencia de la tradición y de la historia que sostienen a los jugadores y a la afición. Al mismo tiempo, son actores a los que inevitablemente los barristas deben recurrir, a los que se les solicita la afiliación, los boletos y la ayuda para viajar a otras ciudades. En tiempos de crisis deportiva y económica, características de los equipos Atlas y Guadalajara durante el desarrollo de esta investigación, las expresiones de inconformidad o de rechazo hacia las directivas - a través de diferentes medios, fuera y dentro de la cancha y de los partidos - fueron reiteradas. Estas tensiones se enmarcan en espacios de poder en los que la directiva, actor con la propiedad legal y económica de la empresa privada, se enfrenta a la afición, heredera de la tradi-

\footnotetext{
${ }^{27}$ Entrevista con Fernando Moncada, realizada por Rodolfo Aceves el 20 de octubre de 2005 en Guadalajara, Jalisco.
}

ción, poseedora simbólica de los derechos de una herencia y de una historia compartida, de un patrimonio común que está más allá de lo económico, de lo material, representado por el equipo. La constante en los partidos del Guadalajara como local, después del despido como director técnico de Benjamín Galindo, exjugador simbólico de las Chivas, fue la expresión colectiva de ofensas dirigidas principalmente a Jorge Vergara, dueño del equipo, intensificadas en los partidos en los que el equipo perdía. De esta manera, era común escuchar a los barristas rojiblancos proferir, a la manera de una porra: "Vergara hijo de puta, hijo de puta, puta, puta, puta, puta" 28 .

Por otro lado, los aficionados rojinegros, inconformes ante la política de su directiva de producir buenos jugadores en su sistema de fuerzas básicas para después venderlos a precios muy elevados, sin importar la desmantelación del equipo, se han expresado, entre otras, de la siguiente manera:

No es posible seguir aguantando a estos "pseudodirigentes" que no sienten el amor al equipo. Los directivos se la han pasado a lo largo de los años, sacando dinero del club rojinegro y haciendo una "pseudodemocracia" al hacer sus elecciones internas con planillas que crean los directivos que están bajo el poder. A través de la Asociación Civil es su mejor escudo para obtener sus recursos con la venta de jugadores como, Márquez, Salazar, Osvaldo, de Pinho, Chato, Zepeda, Corona, Torres, Espinoza, etc., etc. Hay tres cosas graves: que el equipo va cada día más en caída a lo largo de los años, que sigue sin salir campeón para dar alegría a su afición y, la más grave, que la gente no hace nada ni dice nada ${ }^{29}$.

\section{Relaciones con los equipos}

El actor con quien los barristas se sienten más identificados y compenetrados es el equipo de futbol. Para el propósito de esta investigación, entendemos que el equipo está integrado por los jugadores y un cuerpo técnico (director técnico, auxiliares técnicos, doctor, masajista, aguador, etcétera). Para el barrista, el equipo significa un

\footnotetext{
${ }^{28}$ Diario de campo, 24 de agosto de 2005.

$29 \mathrm{http}: / /$ groups.msn.com/atlasbarra51/general.msn
} 
objeto de idolatría y de admiración. Los jugadores y algún técnico adquieren la naturaleza del héroe, del ejemplo a seguir, el dador de la alegría para toda la semana, el que con una jugada o con un gol puede hacer más llevadera la vida cotidiana del aficionado, el que puede marcar una época en el devenir del club de sus amores. La admiración y el compromiso que un aficionado adquiere y desarrolla por y con los jugadores llegan a los terrenos de la incondicionalidad del apoyo a pesar de los malos resultados. El jugador es concebido como un guerrero que se esfuerza por dar la alegría de un triunfo o de un partido intenso a sus seguidores, unas veces con buenos resultados y otras no. Sin embargo, independientemente de esto, las barras demuestran su admiración y su cariño de diferentes maneras: con gritos de aliento, con mensajes de apoyo en las mantas, con cánticos que apelan a su brillantez y entrega. El barrista, en las buenas y en las malas, dentro y fuera del estadio, expresa su lealtad al equipo asistiendo a todos o a la mayoría de los encuentros deportivos, acudiendo a los entrenamientos en las sedes de los clubes, apoyando durante todo el partido, se vaya ganando, empatando o perdiendo, porque el amor a un equipo es cosa seria, es parte de la vida, es un distintivo muy especial. Por eso, gane o pierda, o como dicen los aficionados del Betis de Sevilla: "er Betis manque pierda", y los rojinegros, en un tono un tanto sarcástico: "soy del Atlas aunque gane", la animación al equipo debe ser incondicional.

Sabritas, líder de la Estirpe sagrada del Guadalajara, señala:

Gane o pierda ahí estamos. De hecho, la semana pasada me comentaba uno de los directivos del Club Guadalajara [...] que $[\ldots]$ de repente dejábamos de apoyar y yo le decía no, [...] no dejamos de apoyar al equipo, de repente la gente [...] ha atacado al presidente o a la administración del presidente $[\ldots]$ porque $[. .$.$] se sienten traicionados hasta cierto$ punto por algunos manejos, ustedes están teniendo que pagar un costo alto por algunas decisiones desatinadas que han tomado, pero si te fijas no hemos dejado de apoyar porque afortunadamente estamos enojados pero estamos en la tribuna, y estamos enojados con la directiva, no con el equipo, al equipo se le anima, al equipo, la barra, el grupo, el grupo de animación, la porra [...] no le ha recriminado [...] absolutamente nada, siempre se le ha alentado y ahí estamos. De repente se le exige con cantos, pero nunca se le

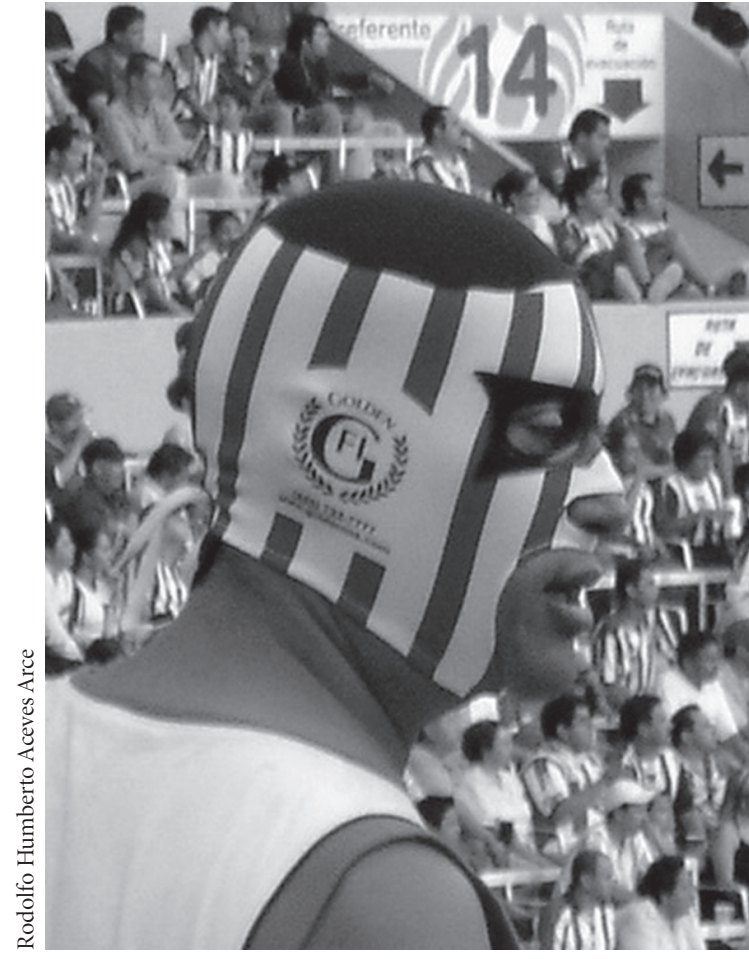

Aficionado en el partido Chivas vs. Necaxa, 17 de septiembre de 2005.

ha recriminado, a mí no me ha tocado, en [...] seis años casi ya, nunca $[. .$.$] yo no recuerdo una ocasión que el grupo de$ animación, la barra como tal, le recrimine algo al equipo ${ }^{30}$.

Por otro lado, la relación entre el equipo y las barras se da casi únicamente en el estadio, ya que son muy escasos los encuentros entre estos actores fuera de ese espacio. Sólo en el club, y en ciertas ocasiones, se presentan los barristas a observar un entrenamiento o un partido de preparación. Pero es muy difícil romper las fronteras para establecer relaciones más estrechas, para que los ídolos accedan a convivir con sus admiradores. Uno de estos escasos momentos se dio cuando los jugadores rojinegros Juan Carlos Medina, César Gradito y Guillermo Rodríguez asistieron al parque El Grillo de la colonia Constitución a

\footnotetext{
${ }^{30}$ Entrevista con Sabritas, realizada por Rodolfo Aceves el 19 de noviembre de 2005 en Guadalajara, Jalisco.
} 
observar los murales atlistas, algunos dedicados a ellos, con sus rostros dibujados, y a convivir con los muchachos del Frente Rojinegro.

\section{Relaciones con otros aficionados}

Los vínculos entre las barras son complejos, no sólo entre las de equipos contrarios, que generalmente se caracterizan por ser hostiles tanto física como simbólicamente y, en el mejor de los casos, indiferentes. También entre las barras de un mismo equipo existen diferencias e incluso golpes. En algunos partidos de la temporada se presentaron actos de violencia entre miembros de barras rojinegras. Estos hechos, extensivos también a los grupos rojiblancos, son producto de las rivalidades, las diferencias de opinión y la disputa por el poder y el reconocimiento: el poder para influir sobre otros grupos, para comandar las prácticas del resto de colectivos cuando en las tribunas se convierten en uno solo, para tener más miembros que se traduzcan en una mayor presencia, pasentirse más fuertes que los otros. El reconocimiento como el más escandaloso, el más desmadroso, el que tiene más aguante, el que siente más los colores del equipo, el más antiguo, el más numeroso, se obtiene del resto de aficionados, de las directivas de los clubes, de los jugadores y de los medios.

De hecho, buena parte de la composición actual de los grupos de animación de ambos equipos se generó, entre otros factores, de las divergencias de opinión entre los líderes de las porras y de las barras. Ahora bien, la visión generalizada de los grupos denominados porras, acerca de su relación con las barras, puede ejemplificarse en el siguiente testimonio de don Pablo, fundador y líder de la Porra Familiar del Atlas:

no he estado de acuerdo, desde que nacieron las barras; sí, desgraciadamente las barras nacieron por influencia precisamente de Centroamérica ¿no?, Argentina, Brasil, Chile [...] y lo peor de todo en un principio, cuando nacieron esas barras, [...] lo que no estábamos de acuerdo nosotras las porras tradicionales es con el comportamiento que han tenido, porque sí era un canto, con puras palabras altisonan-

tes, ¿sí??, sí era, no sé, a lo mejor brincos, pos son a donde se agarran brincando en un momento dado, sin respetar a nadie, $[. .$.$] los cantos desgraciadamente que nacieron conjun-$ to con ésas, con las barras, pos son palabras muy hirientes ¿no?, que nosotros como familia pos definitivamente no, no nos asustamos de oírlas, pero no estamos de acuerdo en muchos aspectos, en muchas palabras que se dicen ¿no? ${ }^{31}$.

Abundando en la relación entre porras y barras, Hugo, dirigente de la Porra Oficial del Atlas, hace referencia a otros aspectos que le desagradan de este tipo de grupos:

Para mí lo que no me gusta de la barra es que sean tan agresivos y armen desmanes dentro del estadio y afuera, es en lo que yo no estoy de acuerdo, yo creo que todos debemos tomar conciencia de que es un partido de futbol y ese partido lo debemos de ver como un deporte, se pierda o se gane pos vámonos, ¿no? Pero muchos ya lo agarran de vandalismo en la calle, ya no es que vayas a, a ver un partido de futbol, sino que ya vas a golpear gente inocente o niños, entonces ya, mucha gente se está retirando de los estadios por eso, porque ya ven que hay barras y ya dicen agresión, ya dicen delito, ya eso es lo que mucha gente platica, entonces ya mucha gente se está retirando del estadio por eso, porque son barras y es violencia, entonces, pues yo creo que yo no estoy de acuerdo con ellos ${ }^{32}$.

Los aficionados que no pertenecen a las barras o porras tienen opiniones encontradas sobre el tema. Hay quienes creen que es un fenómeno copiado, artificial, ajeno a las costumbres mexicanas relativas al futbol; otros consideran que dan colorido y sabor a la tribuna. Una buena parte cree que sus actitudes son violentas y nocivas para el ambiente familiar que ha caracterizado al ámbito futbolero en nuestro país y en nuestra ciudad. Tampoco faltan los que, seducidos por el entusiasmo de la barra, se unen a ellos en algunos partidos sin la intención de afiliarse a los grupos, sólo con la finalidad de vivir intensamente la experiencia. Lo que es cierto es que, a pesar de que no hay una fuerte división física entre los barristas y el resto del público, la tendencia de éste es mantener la distancia y no

\footnotetext{
${ }^{31}$ Entrevista con don Pablo, realizada por Rodolfo Aceves el 25 de octubre de 2005 en Guadalajara, Jalisco.

${ }^{32}$ Entrevista con Hugo, realizada por Rodolfo Aceves el 8 de noviembre de 2005 en Guadalajara, Jalisco.
} 
relacionarse demasiado con las barras. Puede que sus cánticos y la vistosidad de sus prácticas sean muy atractivos y hasta entonados y compartidos por el público, pero no existe una comunicación estrecha entre ambos. Unos y otros prefieren mantener sus espacios $y$, a menos que haya una provocación o intrusión en sus ámbitos, las relaciones permanecen en un marco de respeto, uno sui generis que puede estar salpicado de mentadas de madre y otras ofensas. Para Alfredo Torres, exjugador simbólico del Atlas, mejor conocido como El Pistache, las barras representan "demasiados cambios que antes, o las porras eran verdaderas porras, ahora son porros, $[\ldots]$ porras ya no hay, $[\ldots]$ ahora en su forma de hablar $[\ldots]$ está más dura la cosa, $[\ldots]$ más bravos, más porras bravas" 33 .

De los testimonios anteriores podemos concluir que las barras son vistas por los porristas y por otros aficionados como grupos violentos, vándalos, desmadrosos y ofensivos que han venido a cambiar una tradición de asistencia a los estadios y de apoyo a los equipos de futbol de carácter familiar, amistosa, agradable, respetuosa.

\section{Relaciones con las autoridades civiles}

Con las autoridades civiles, es decir, policías y bomberos municipales, los barristas mantienen una relación tensa, dado que se les percibe como grupos altamente violentos. El día del partido, los cuerpos de seguridad observan cuidadosamente las actividades de los barristas. Antes de su entrada a las graderías, los policías registran a cada miembro de la barra con el objetivo de prohibir el ingreso de armas blancas o de fuego, así como de artefactos con dinamita. De hecho, las autoridades civiles, junto con las directivas de los clubes, determinan las zonas de acceso y de permanencia de estos grupos en el estadio. Incluso, antes de partidos con gran audiencia, como el clásico Atlas-Guadalajara, reúnen a los líderes de las barras de cada equipo para ponerse de acuerdo en las medidas de seguridad y de comportamiento, como la salida de contingentes de aficionados desde distintos puntos

\footnotetext{
${ }^{33}$ Entrevista con Alfredo Torres, realizada por Rodolfo Aceves el 1 de noviembre de 2005 en Guadalajara, Jalisco.
}

de la ciudad al estadio, custodiados por policías municipales, y la invitación a evitar actos de violencia, so pena de detenciones y desafiliaciones.

Dentro del estadio, las barras son seguidas de cerca por el cuerpo policial y de protección civil. Siempre son rodeadas y observadas desde la cancha y desde la tribuna. Junto con los policías y bomberos, se colocan elementos de seguridad privada contratados por cada club, para reforzar las estrictas medidas de seguridad, que generalmente son violadas por el ingreso de droga, sobre todo marihuana, para el consumo de algunos barristas. Los líderes de los grupos, refiriéndose al comportamiento de los policías, comentan que tienen mucho que ver en la generación de actos violentos dentro y fuera del estadio. Es decir, existe una autopercepción, por parte de los barristas, de que el comportamiento de sus integrantes es difícil de controlar, pero también hacen énfasis en la provocación que los cuerpos de seguridad ejercen sobre ellos. Así, una delgada línea mantiene el respeto entre ambas partes. Sobre esto, Candelario, coordinador del Frente Rojinegro, expresa:

Siempre ha habido choque con la policía de Guadalajara y con las barras [...] Nosotros lo que pensamos es que a lo mejor ya mandan a los policías [...] muy cansados, con una rutina muy pesada, y es obvio que ellos llegan al relajo, llegan y ven gente pues que no se comporta como se debe de comportar y obviamente ellos se desesperan. Deben estar capacitados pues, psicológicamente para esos momentos, pero yo en lo personal pienso que [...] los mandan [...] con mucha carga de trabajo, y pienso que es por eso que existe el choque, por la carga de trabajo de ellos, lo pesado que es estar ahí todo el día y por la falta de conciencia también de nosotros pues, de que a veces nos comportamos de alguna forma muy inmadura pues ${ }^{34}$.

La constante para el barrista es ver en el policía o en el miembro del cuerpo de seguridad a un enemigo, a un aguafiestas, a un actor no deseado en el universo futbolero. No sólo en el barrio, sino también en las tribunas, el barrista se ve despojado de su libertad de actuación por la presencia de "la ley". Para ejemplo de esta comple-

\footnotetext{
${ }^{34}$ Entrevista con Candelario Chávez, realizada por Rodolfo Aceves el 30 de septiembre de 2005, en Guadalajara, Jalisco.
} 
ja relación, se presenta un breve fragmento de un cántico en el que se califica despectivamente a los cuerpos policiacos:

\author{
Yo te quiero la acade \\ Yo te quiero, eres mi vida \\ Siempre te voy a alentar \\ Aunque me siga la policía, putos [esta última palabra pro- \\ nunciada con mayor fuerza] \\ Vayas a donde vayas \\ Ésta es tu hinchada \\ La que te anima $[. .$.
}

\section{Relaciones con los medios de comunicación}

Los medios de comunicación juegan un papel importantísimo en la difusión del futbol. No en vano éste es el deporte con más cobertura en los periódicos, en la radio, en la televisión y en la Internet. Ya observamos cómo algunos de los líderes de barras tuvieron su primer contacto con las prácticas sudamericanas que después adoptaron a través de la televisión. Pues bien, los medios locales y nacionales no pueden dejar de lado el fenómeno de las barras, sobre todo por lo que pueden aportar a las notas periodísticas en el caso de actos violentos, principalmente. Domingo a domingo somos testigos, en los resúmenes televisivos de las jornadas, del llamado "color" de las tribunas de los estadios, donde invariablemente aparecen los barristas bailando, cantando, gozando, sufriendo. Sin embargo, aparte de ser tomados en cuenta como ornato de las tribunas o, por el contrario, como los villanos de los estadios, los medios generalmente sólo se acercan a los miembros de las barras en momentos en que hay que buscar la nota, por ejemplo, en momentos de crisis de los equipos, como los vividos por ambos clubes durante el desarrollo de esta investigación. Candelario se refiere a su relación con los medios de la siguiente manera:

Cuando hay violencia, simplemente ellos lo publican [... pero no, a nosotros nos buscan nada más cuando son así, te digo, cosas amarillistas, cuando venden a De Pinho, así, o sea, situaciones que tú dices que es mejor por ejemplo, que por qué no nos buscan ahorita que está mal el equipo para transmitirle a la gente ante los medios que realmente deben estar apoyando, o sea, no, la prensa es muy amarillista, qué te digo, nos buscan nada más en esos momentos, y cuando sean problemas de la barra así de violencia no nos buscan, como que se mantienen al margen pues ${ }^{35}$.

Por otro lado, es significativo que los miembros de las barras y de las porras siguan de cerca su pasión, alimenten su afición desde lo que los medios les ofrecen. En especial, la radio. Actualmente, ésta cumple una función importante en la difusión de este deporte, sobre todo en el cuadrante de A. M., aunque ya fuertemente competida y relegada por la televisión y la Internet. Todavía durante 2005 existía una estación tapatía que se dedicaba exclusivamente a la transmisión de partidos y de programas especializados en futbol: Futbol Gigante, en el 1480 de A. M. Además, otra estación, la Súper Deportiva, en el 1370 de A. M., dedicaba una hora de expresión semanal a los aficionados rojinegros, principalmente a los barristas, los viernes a las 12:00 horas. A su vez, Luis Felipe Martínez, líder y fundador de la Legión 1908 de Chivas, coordina un programa en la Internet, en el cual transmite música y expone sus puntos de vista, junto con otros compañeros, acerca del fenómeno del futbol y de las barras.

En general, los líderes de barras y porras se mantienen en contacto con el futbol a través de los medios, en especial cuando no hay partidos o ya terminó el torneo, como recurso para suplir una carencia que podría considerarse como trascendente:

si no hay futbol, pues ya entre semana yo estoy escuchando, pues prácticamente diario, algo relacionado con el futbol y programas, ¿no?, de radio, de televisión, [...] los medios escritos y todo, ¿no?, pero todo gira, o sea, toda la vida misma, mi vida misma gira alrededor de lo que es el futbol, definitivamente ${ }^{36}$.

\footnotetext{
${ }^{35}$ Entrevista con Candelario Chávez, realizada por Rodolfo Aceves el 30 de septiembre de 2005, en Guadalajra, Jalisco.

${ }^{36}$ Entrevista con don Pablo, realizada por Rodolfo Aceves el 25 de octubre de 2005 en Guadalajara, Jalisco.
} 


\section{Un día de partido en la vida de un líder de barra}

Con el objeto de presentar un testimonio que permita entender de manera más profunda la significación del mundo futbolero para un barrista, a continuación se expone un breve texto que trata del acontecer de un día de partido de futbol para un líder de una barra de las Chivas.

Sabritas nació hace treinta años en la ciudad de San Luis Potosí. Reside en Guadalajara desde que tenía tres meses de edad. Vive en casa propia, al noroeste de la zona metropolitana tapatía, en el fraccionamiento Villas del Centinela, municipio de Zapopan. Está casado y tiene una hija de un año de edad. Trabaja como ejecutivo de ventas de una empresa dedicada a la elaboración de calcomanías con base en la técnica de la flexografía, labor que le permite estar libre de obligaciones los fines de semana. De hecho, éste es un empleo que buscó para evitar que sus funciones como dirigente de barra no se interrumpieran, especialmente los sábados. Según recuerda, desde hace unos veinte años sólo ha dejado de asistir a un partido de las Chivas en su estadio unas veinte veces, todas ellas motivadas por una causa de fuerza mayor. En más de una ocasión sus funciones le han provocado complicaciones en su vida personal y laboral, pero éstas no lo han hecho renunciar a su cargo como líder de la Estirpe Sagrada.

Para Sabritas, un día de partido de futbol del equipo de su corazón, las Chivas Rayadas del Guadalajara, es un día muy especial. Desde que se levanta de la cama, su mente está puesta en todo lo que tiene que hacer como líder de la Estirpe Sagrada. Muchas veces lo despiertan los telefonazos de aquellos despistados que no recuerdan en dónde y a qué hora se tienen que ver (sobre todo si no juegan como locales en el Estadio Jalisco) o de los que no alcanzaron a realizar el depósito para pagar el boleto. $\mathrm{Sa}$ britas atiende las llamadas y trata de resolver las dudas de sus correligionarios, y además se comunica con los miembros del grupo que lo apoyan en tareas de organización de la barra.

Posteriormente, al tiempo que convive con su familia, se dispone a arreglar la mochila que le sirve de depósito para los boletos, las listas de asistencia y las credenciales de los miembros de la Estirpe. Algo muy especial para él es escoger las camisetas que llevará en la mochila para usar

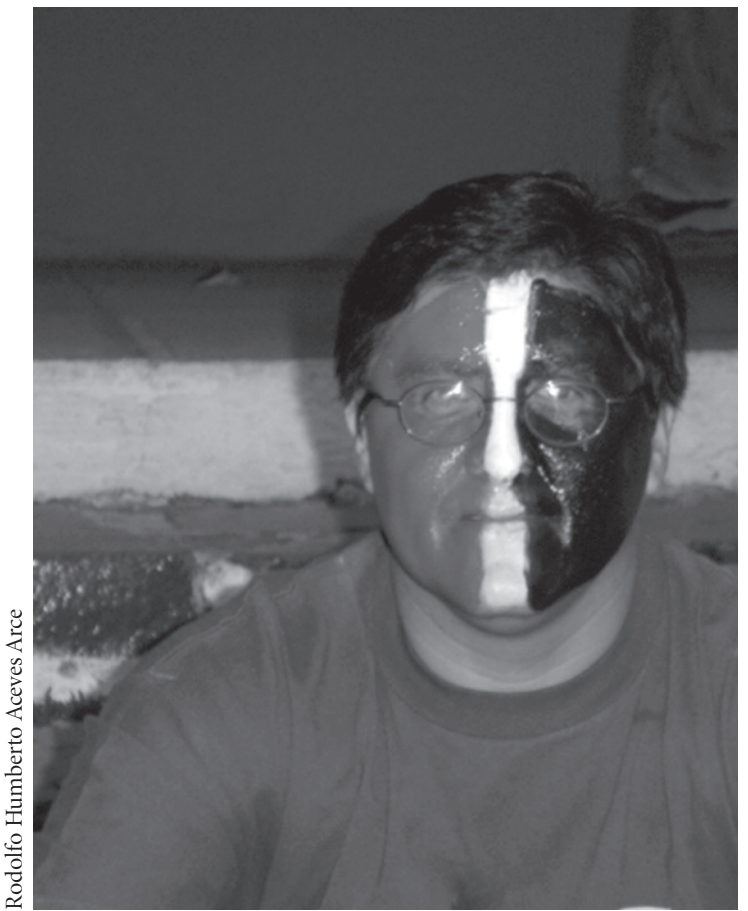

Aficionado en el partido Atlas vs. Jaguares, 24 de septiembre de 2005 .

en el estadio. Generalmente carga con tres: una copia del diseño con el que el equipo fue campeón por última vez, la del torneo Verano 1997; la primera playera oficial de la era Vergara, su favorita, por ser amplia y cómoda, además de que no tiene publicidad impresa, y la playera oficial del centenario del club, la cual no le parece muy cómoda por quedarle ajustada. Estas camisetas, además de ser parte integral de su atuendo como barrista, cumplen una función de amuleto: Sabritas usa la que él cree que le da buena suerte al equipo, la que viste cuando gana. Si por alguna circunstancia él cambia de camiseta en otro partido y su equipo pierde, entonces no duda en volverse a poner en el próximo juego aquella que usó la última vez que las Chivas ganaron. Y si en un partido las cosas no están saliendo bien, puede ser que cambie en las tribunas de playera para tratar de que la suerte juegue a favor de los rojiblancos.

Antes de salir de su casa, se despide de su esposa e hija y se dirige al estadio en su automóvil. En el camino se detiene en algún puesto de tacos o de tortas para calmar 


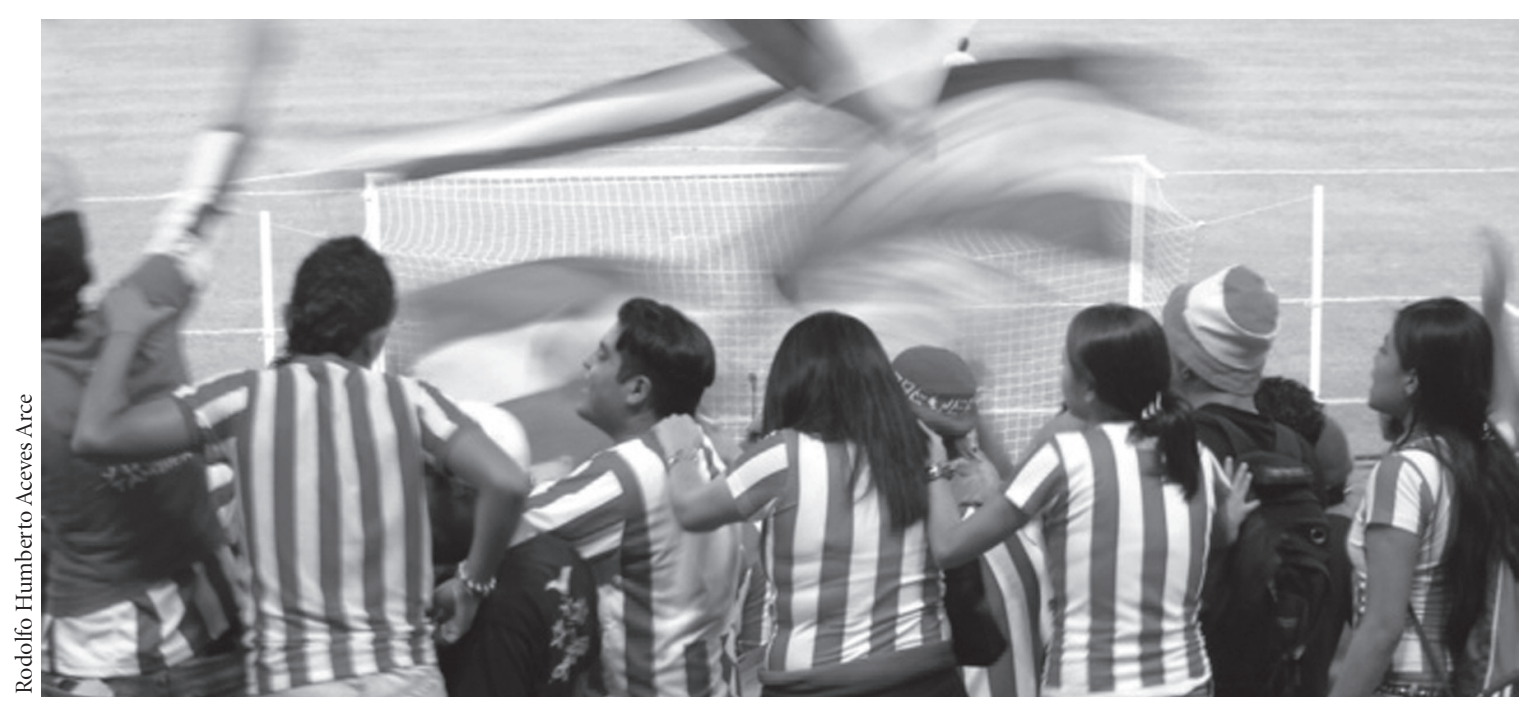

Aficionados en el partido Chivas vs. Morelia, 29 de octubre de 2005.

el hambre. Ya en las afueras del estadio, se dirige al lugar de costumbre, la puerta número 12, para encontrarse con sus amigos e integrantes de la Estirpe. Ahí, entrega credenciales y boletos mientras bebe una cerveza, sólo una, para no dar una mala impresión a sus compañeros y a las autoridades, especialmente a los policías que observan permanentemente las acciones de los barristas. También conversa con los demás aficionados acerca de los partidos de la jornada y la forma en que su equipo juega, sus aciertos y errores, sus posibilidades en el o los torneos en que participa. Poco antes del inicio del partido, o incluso durante el mismo, entrega a un funcionario del club, en una de las oficinas del estadio, el importe de los boletos cobrados y regresa las entradas sobrantes.

Ya en el estadio, lo primero que hace es revisar la disposición de los miembros de la Estirpe y la de los policías. Se dirige a estos últimos para comunicarles que su grupo tendrá un buen comportamiento y les pide que los traten de buena manera, sin provocaciones ni violencia. Ahora sí, cumplidos estos requisitos autoimpuestos, de cuya utilidad está convencido, se acomoda en el grupo y comienza a cantar y a alentar, a gozar y a sufrir, a gritar y a saltar. Mientras, está atento a su gente y llama la atención a los que no participan o lo hacen tibiamente, al mismo tiempo que vigila su comportamiento.
$\mathrm{Al}$ igual que muchos de sus correligionarios, experimenta variadas emociones y sentimientos: alegría, tristeza, coraje, impotencia, angustia, frustración, amor y odio. En un partido puede experimentar todos y cada uno de ellos, lo que tal vez no ocurra en varias semanas en otros ámbitos de su vida. Su garganta siempre está lista para gritar y para cantar, especialmente cuando entona colectivamente uno de sus cantos favoritos, el que dice:

\section{Chivas, chivas de mi vida \\ Eres la alegría \\ De mi corazón. \\ Sabes, todo lo que siento \\ Lo llevo aquí adentro \\ De mi corazón.}

Una vez terminado el encuentro, vigila que sus compañeros abandonen las tribunas sin provocar problemas y sale por la misma puerta por la que entró, la 12, para platicar sobre la jornada, generalmente junto al depósito de cerveza ubicado sobre la puerta en cuestión. Si se ganó, se disfruta y se comparte la alegría y la cerveza. Si se empató o se perdió, también se comparte el sentimiento, generalmente de frustración, aunque puede que éste se suavice si los jugadores se brindaron y a pesar de ello no ganaron. Casi infaltable, la cerveza adereza estos momen- 
tos. Si los ánimos están arriba, el festejo se sigue en alguno de los bares cercanos al estadio y se prolonga durante una o dos horas. Si no, el destino es el hogar, en donde se descansará después de tanta adrenalina descargada. La conciliación del sueño tendrá que ver, en mayor o menor medida, con el resultado del partido. Y al día siguiente, en el trabajo o con la familia, habrá que festejar el triunfo o aguantar la carrilla por la derrota, especialmente si el equipo que la propinó fue el Atlas o el América. Así empezará una semana de actividades que tendrá como cierre la celebración de una nueva ceremonia, un nuevo partido de futbol de las Chivas, en el Jalisco o en cualquier otro estadio del país.

\section{CONCLUSIONES}

Las barras futboleras tapatías pueden ser consideradas ejemplos del neotribalismo maffesoliano ${ }^{37}$. En su origen, estos colectivos responden a la necesidad de formar conjuntos de aficionados para apoyar a los equipos de primera división de una forma diferente, más intensa, la cual implica una ruptura con la tradición de las porras. En el estadio, sus prácticas requieren de la proximidad física de sus integrantes, caracterizada por el contacto codo a codo, por el roce constante, el abrazo entre unos y otros que fortalece el "nosotros". Esto nos remite a ciertos atributos de los grupos sociales que Maffesoli denomina nuevas tribus: el plano del estar juntos, de la intensidad del momento, del goce del mundo tal cual es (Maffesoli, 2004: 28), así como las experiencias expresadas en el "darse calor, codearse, rozarse" como fundamentos de la ética de estos grupos (Maffesoli, 2004: 64).

\footnotetext{
${ }^{37}$ Además de lo propuesto por Maffesoli, algunos conceptos sobre grupos emanados de perspectivas sociológicas pueden ser útiles para caracterizar a las barras futboleras, tales como grupos reales, comunidad (Tönnies), grupos primarios (H. C. Cooley), así como los criterios de clasificación para grupos sociales de G. Gurvitch: contenido, tamaño, duración, ritmo, relaciones entre miembros, bases de creación (voluntaria, etc.), acceso a la membresía (abierta, cerrada, etc.), grado de organización, función, orientación, relación con la sociedad en su conjunto, vínculos con otros grupos, tipos de control social, tipo de autoridad, grado de unidad o cohesión (Montaño, 1977: 10-13). Sin embargo, consideramos que la perspectiva maffesoliana es una lente con la que estos grupos pueden observarse de mejor forma.
}

Como pudimos observar en el desarrollo del artículo, entre los miembros de las barras del Guadalajara y del Atlas existe un interés por mantenerse unidos en la fidelidad y el apoyo a un equipo de futbol. Esto, aunado a su composición, en su mayoría de jóvenes varones de clase media baja y clase baja, nos estimula a reflexionar sobre la existencia de movimientos juveniles de carácter popular con intencionalidades más allá de lo político o de lo económico. De esta manera, estos grupos muestran una racionalidad caracterizada por una socialidad empática: compartir emociones, compartir afectos (Maffesoli, 2004: 31) alrededor de la pasión por un mismo equipo de futbol. De acuerdo con Maffesoli, en un espectáculo como el futbol se acentúa la dimensión táctil de la existencia social, se expresa lo que denomina la constante antropológica del placer popular como placer de multitud o grupal para entender la compulsión a congregarse (Maffesoli, 2004: 153).

La estructura interna y el funcionamiento de estos grupos demuestran que existen ciertos acuerdos que implican un grado de organización para cubrir sus necesidades, con dosis de flexibilidad y vaivenes entre la formalidad y la informalidad. Existen líderes que coordinan las labores del grupo y miembros que las ejecutan, sin que esta división de labores implique una rigidez en la planeación y la realización de las mismas. Por otro lado, estos colectivos sólo se encuentran registrados ante los clubes de futbol y, en su mayoría, carecen de normas y estatutos escritos. Las reglas para integrarse y participar en ellos son conocidas y compartidas sin la necesidad de que sean expresadas a través de documentos impresos. Asimismo, la contabilización de sus miembros es una tarea complicada: a pesar de que los colectivos rojinegros cuentan con un número limitado de integrantes y, por el contrario, los rojiblancos no, los asistentes a los partidos varían de semana a semana. No siempre son los mismos, aunque existe la obligación moral de apoyar al equipo en cada compromiso deportivo. Igualmente, el número de barristas se incrementa con la participación de aficionados que no están registrados en el padrón de cada grupo. Además, cada año, cuando se abren los registros de los clubes, los miembros vienen y van: como podemos encontrar a los que asisten desde que se fundó el grupo, también están aquellos que sólo se presentan a pocos partidos en una temporada y ya no vuelven. 
La socialización cumple un papel fundamental entre los jóvenes que integran estos colectivos. La barra se convierte en un espacio idóneo para la generación de amistad, de solidaridad. La barra es, tal vez, uno de los pocos espacios en que sus integrantes pueden sentirse satisfechos, integrados, importantes. Los espacios de interacción no se limitan al estadio, sino que se amplían al barrio, a la escuela, al parque, a los lugares donde se celebran otro tipo de eventos culturales como conciertos de rock, de punk o de cumbia villera.

Las relaciones que establecen estos grupos con otros actores son fluctuantes. Estos vínculos también demuestran la flexibilidad de la organización de estos colectivos, adecuándose a la satisfacción de sus necesidades y a las circunstancias. Los directivos de los clubes requieren de su apoyo pero también se alejan de ellos: en ocasiones los auxilian para la adquisición de boletos en viajes a otras ciudades, pero no intentan establecer lazos firmes y duraderos con ellos. Los jugadores de los equipos limitan su interacción al espacio y el tiempo de los partidos, salvo algunas excepciones. Los sentimientos de los aficionados do, de atracción ante sus prácticas y, por otro, de repulsión ante las mismas o de rechazo cuando éstas derivan en violencia. Las autoridades, exceptuando casos contados, tienden a criminalizarlos, aun cuando no todos sus integrantes son violentos, sin establecer diálogo con ellos u operativos efectivos en diversos espacios y tiempos que impliquen un mejor control de su comportamiento; los medios de comunicación tienden a observarlos como ornato del espectáculo futbolístico, como los ejecutantes del carnaval del fin de semana y, al mismo tiempo, como generadores de noticia en los casos de violencia.

Finalmente, cabe resaltar la relevancia del futbol en la vida diaria para algunos de los miembros de estos colectivos. Su identificación con el equipo llega a ser tan intensa que suelen mostrarla a través de diversas prácticas, símbolos y discursos en diferentes ámbitos: la escuela, el trabajo, el hogar, el barrio. Sin embargo, esta identificación se vincula con muchas otras: la de madre o padre, la de hija o hijo, la de estudiante o trabajador. Es decir, como barrista rojiblanco o rojinegro no se vive todo el tiempo, pero no por ello esta pertenencia deja de ser una característica so-

bresaliente de los integrantes de una tribu futbolera. En este sentido, apuntamos una característica más de la socialidad descrita por Maffesoli: la multiplicidad de papeles desempeñados por las personas tanto en su actividad profesional como en las diversas tribus que integran, los cambios de traje y escena según sus gustos en los diversos juegos del theatrum mundi (Maffesoli, 2004: 153).

\section{Bibliografía}

Calderón Cardoso, Carlos, 2001, Crónica del futbol mexicano: vientos de cambio (1997-2001), Clío, México.

Doñán, Juan José, 2001, Oblatos-Colonias. Andanzas tapatías, Ed. Campo Raso, Guadalajara.

Fábregas, Andrés, 2001, Lo sagrado del rebaño. El futbol como integrador de identidades, El Colegio de Jalisco, Zapopan.

Ferguson, R. Brian, 2000, “Tribu, organización tribal”, en Thomas Barfield (ed.), Diccionario de antropología, Siglo XXI, México, pp. 522-523.

Foer, Franklin, 2005, How Soccer Explains the World, Harper Perennial, Nueva York.

Gómez, Jaime, 1997, Chivas. La historia oficial del Guadalajara, Ágata, Guadalajara.

Giner, Salvador, Emilio Lamo de Espinosa y Cristóbal Torres (eds.), 1998, Diccionario de sociología, Alianza, Madrid.

Maffesoli, Michel, 2004, El tiempo de las tribus. El ocaso del individualismo en las sociedades posmodernas, Siglo XXI, México.

Montaño, Jorge, 1977, Los grupos sociales, Asociación Nacional de Universidades e Instituciones de Educación Superior, México.

Nuño, Alfonso y Gregorio González, 1991, El Atlas en sus primeros 75 años. Edición conmemorativa, Impre-Jal., Guadalajara.

Pliego, Roberto, 2006, Corazón chiva: cien años, Planeta, México.

Sotelo, Greco, 1999, Chivas. La construcción de un orgullo, Clío, México.

\section{Documentos en Internet}

http://groups.msn.com/atlasbarra51/general.msn, última consulta abril de 2006.

http://www.pasiontuza.com, última consulta abril de 2006. 